\title{
Genetic influences in gastro-oesophageal reflux disease: a twin study
}

See end of article for authors' affiliations

\section{Correspondence to:} Dr N J Trudgill, Department of Gastroenterology, Sandwell General Hospital, West Bromwich B71 4HJ, UK;

nigel.trudgill@swbh.nhs.uk

Accepted for publication 3 March 2003
Background: A number of families have been described which include multiple members with symptomatic, endoscopic, or complicated gastro-oesophageal reflux disease (GORD). First degree relatives of patients with GORD are more likely to suffer with GORD symptoms. These observations raise the possibility of a genetic contribution to the aetiology of GORD.

Aims: To determine the relative contribution of genetic factors to GORD by evaluating GORD symptoms in monozygotic (MZ) and dizygotic (DZ) twins.

Methods: A total of 4480 unselected twin pairs, identified from a national volunteer twin register were asked to complete a validated symptom questionnaire. GORD was defined as symptoms of heartburn or acid regurgitation at least weekly during the past year.

Results: Replies were obtained from 5032 subjects (56\% response rate). A total of 1960 twin pairs were evaluable: $928 \mathrm{MZ}$ pairs (86 male pairs, mean (SD) age 52 (13) (range 19-81) years) and 1032 DZ pairs (71 male pairs, mean age 52 (13) (20-82) years). The prevalence of GORD among both groups of twins was $18 \%$. Casewise concordance rates were significantly higher for $M Z$ than DZ twins $(42 \%$ v $26 \% ; p<0.001)$. Multifactorial liability threshold modelling suggests that additive genetic effects combined with unique environmental factors provide the best model for GORD. Heritability estimates suggest that $43 \%$ (95\% confidence interval $32-55 \%$ ) of the variance in liability to GORD is due to additive genetic factors.

Conclusions: There is a substantial genetic contribution to the aetiology of GORD.
G astro-oesophageal reflux disease (GORD) is one of the most common disorders in the Western world. Community surveys suggest that $14-20 \%$ of the population report heartburn or acid regurgitation on a weekly basis. ${ }^{12}$ Frequent GORD symptoms are a major risk factor for oesophageal adenocarcinoma, ${ }^{3}$ the incidence of which has been rising more rapidly than any other cancer in the last three decades. ${ }^{4}$ Despite progress in understanding the pathophysiology of GORD, its aetiology is largely unknown.

Two lines of evidence suggest familial factors may be important. Firstly, a number of reports describe multiple family members with symptomatic or endoscopic GORD, Barrett's oesophagus, and oesophageal adenocarcinoma. ${ }^{56}$ Secondly, there is evidence of aggregation of GORD symptoms within families of patients with GORD, ${ }^{78}$ which may indicate either shared exposure to environmental influences or a genetic predisposition. Furthermore, there are marked sex and ethnic differences in the incidence of Barrett's oesophagus and oesophageal adenocarcinoma, suggesting a significant genetic contribution to their aetiology. ${ }^{4}$

Studies of monozygotic (MZ) and dizygotic (DZ) twins may give useful insights into the relative contributions of environmental and genetic factors to a disease. A recent study of GORD symptoms in a group of Swedish twins has suggested that there is a significant genetic contribution to the aetiology of GORD symptoms. ${ }^{9}$ We have therefore studied GORD symptoms in $\mathrm{MZ}$ and DZ twins.

\section{METHODS}

\section{Subjects}

All 4480 pairs of twins from the St Thomas' Adult UK Twin Registry ${ }^{10}$ were invited to take part in the study. All are healthy volunteers who were originally recruited through a national media campaign and from twin registers. ${ }^{11}$ The zygosity of the twins was established using a standardised questionnaire and genotyping in cases of uncertainty. ${ }^{12}$

\section{Questionnaire}

Each subject was sent a 25 item questionnaire. The questionnaire recorded demographic details, symptoms of heartburn and acid regurgitation during the past year, and potential risk factors for GORD (alcohol, body mass index (BMI), drug therapy (anticholinergics, benzodiazepines, calcium antagonists, nitrates, oral contraceptives, and hormone replacement therapy), parental family history of upper gastrointestinal disease, handedness, and smoking). The questionnaire has been validated in 50 community subjects. It has good validity for a diagnosis of GORD (based on at least weekly symptoms of heartburn or acid regurgitation) compared with an interview (kappa 0.72) and moderate reliability on re-test four weeks later in 30 of the subjects who responded to a second questionnaire by post (kappa 0.50).

\section{Twin studies}

An individual's phenotype is the result of the effects of both genotype and environment. To study the source of individual differences (that is, the variance) in a phenotype, genetically related subjects are required and twins are just such a group. MZ twins have the same genes and DZ twins share, on average, $50 \%$ of their segregating genes. It is assumed that both types of twins have been exposed to the same family or shared environment ${ }^{13}$ and that therefore any greater similarity between MZ than DZ twins is due to genetic influences.

\section{Analysis}

A subject was considered to have GORD if they had suffered either heartburn or acid regurgitation at least weekly during

Abbreviations: GORD, gastro-oesophageal reflux disease; $M Z$ monozygotic; DZ, dizygotic; BML, body mass index; LOS, lower oesophageal sphincter; TLOSR, transient lower oesophageal sphincter relaxation. 
Table 1 Demographic details of the twins studied

\begin{tabular}{|c|c|c|c|}
\hline & $\begin{array}{l}\text { Monozygotic twins } \\
(n=1856)\end{array}$ & $\begin{array}{l}\text { Dizygotic twins } \\
(n=2064)\end{array}$ & $\mathrm{p}$ Value \\
\hline Age (y) & $51(19-81)^{*}$ & $52(20-82)^{*}$ & 0.13 \\
\hline Female & $91 \%$ & $93 \%$ & 0.05 \\
\hline At least weekly GORD symptoms & $18 \%$ & $18 \%$ & 0.98 \\
\hline Body mass index $\left(\mathrm{kg} / \mathrm{m}^{2}\right)$ & $25(14-47)^{*}$ & $25(15-54)^{*}$ & 0.01 \\
\hline Ever smoked & $36 \%$ & $45 \%$ & $<0.01$ \\
\hline Excess alcoholt & $5 \%$ & $6 \%$ & 0.54 \\
\hline Anticholinergic drug therapy & $7 \%$ & $6 \%$ & 0.18 \\
\hline Oral contraceptive or HRT & $24 \%$ & $26 \%$ & 0.17 \\
\hline Parental family history of upper GI disease & $26 \%$ & $24 \%$ & 0.15 \\
\hline Right handed & $88 \%$ & $88 \%$ & 0.92 \\
\hline \multicolumn{4}{|c|}{$\begin{array}{l}\text { p values are corrected for relatedness of the twins. } \\
{ }^{*} \text { Mean (range). } \\
\text { tExcess alcohol intake defined as }>28 \text { units per week for a man and }>21 \text { units per week for a woman. } \\
\text { GORD, gastro-oesophageal reflux disease; HRT, hormone replacement therapy; GI, gastrointestinal. }\end{array}$} \\
\hline
\end{tabular}

Table 2 Concordance rates for gastro-oesophageal reflux disease in monozygotic and dizygotic twins

\begin{tabular}{lrllll}
\hline Twin type & Total pairs & Discordant pairs & Concordant pairs & $\begin{array}{l}\text { Pairwise } \\
\text { concordance rate* }\end{array}$ & $\begin{array}{l}\text { Casewise } \\
\text { concordance rate* }\end{array}$ \\
\hline $\begin{array}{l}\text { Monozygotic } \\
\text { Dizygotic }\end{array}$ & 928 & 190 & 70 & $27(22-32) \%$ & $42(36-49) \%$ \\
\hline
\end{tabular}

* $95 \%$ confidence intervals in parentheses.

the previous year. Subjects who had been pregnant during the previous year and who had GORD symptoms only while pregnant were not considered to have GORD.

Concordance is a measure of the proportion of co-twins of affected twins that have the disorder themselves. Pairwise concordance is the probability that a twin is affected by a disorder given that at least one member of the pair is affected. It is calculated from the formula $\mathrm{c} / \mathrm{c}+\mathrm{d}$ (where $\mathrm{c}$ is the number of concordant cases and $\mathrm{d}$ discordant cases). ${ }^{14}$ Casewise concordance is the probability that a twin is affected given that the co-twin is affected. It is calculated from the formula $2 \mathrm{c} / 2 \mathrm{c}+\mathrm{d} .{ }^{14}$ The risk ratio expresses the relative magnitude of the risk of GORD in a MZ twin compared with a DZ twin, if their co-twin has GORD.

\section{Genetic modelling}

Quantitative genetic model fitting is based on comparison of the covariance (or correlation) of the disorder between MZ and DZ twins. ${ }^{15}{ }^{16}$ It allows separation of the observed phenotypic variance into additive A (multiple small genetic effects) and dominant $\mathrm{D}$ genetic components, and environmental components shared by both twins $\mathrm{C}$ and unique to each twin E. The heritability estimate is the proportion of variation in liability to a disorder in a population that can be explained by genetic variance. Heritability is calculated from the ratio of genetic variance $(\mathrm{A}+\mathrm{D})$ to total phenotypic variance $(\mathrm{A}+\mathrm{D}+\mathrm{C}+\mathrm{E})$.

The maximum likelihood modelling method used in twin study analysis assumes that variation in the underlying liability of the disorder is normally distributed. ${ }^{15}$ The correlation in liability among twins can be estimated from the frequencies of GORD concordant and GORD discordant pairs using a multifactorial liability threshold model. ${ }^{15}{ }^{17} 18$ Thus the significance of the variance components $\mathrm{A}, \mathrm{C}$, and D is assessed by removing each in submodels and testing the deterioration in fit compared with the full model. The purpose of the model fitting procedure is to explain the pattern of observed variances and covariances using as few parameters as possible.

\section{Statistical analysis}

Demographic differences between MZ and DZ twins were compared using generalised estimating equations, which cor rect for relatedness of the twins in a pair. The difference in concordance rates between MZ and DZ twins was compared using the $\chi^{2}$ test. Logistic regression analysis was used to assess the independent contribution of variables (age, alcohol, BMI, drug therapy, sex, handedness, parental family history of upper gastrointestinal disease, and smoking) to GORD. In genetic modelling, submodels were compared with the full model by hierarchic $\chi^{2}$ tests and the significance of change in the $\chi^{2}$ goodness of fit statistic was assessed. Data handling, preliminary analyses, and genetic modelling were performed using STATA. ${ }^{19}$

\section{RESULTS}

The questionnaire was completed by 5032 subjects (56\% response rate). A total of 1960 twin pairs were evaluable: 928 MZ pairs and 1032 DZ pairs. Demographic details of the two groups are shown in table 1 . The two groups were well matched for age, drug therapy, excess alcohol, parental family history of upper gastrointestinal disease, and handedness but DZ twins had a higher BMI, were more likely to have smoked, and to be female. Non- responders were more likely to be male (male 23\% v8\%) and younger (mean age 43 (range 18-80) years $v 52$ (19-81) years). However, the distribution of MZ and DZ twins was virtually identical (MZ 49\% v 47\%).

Thirty six twins had suffered GORD symptoms only during pregnancy and were excluded from the study. The prevalence of GORD was identical in both groups of twins (18\%).

The concordance rates for GORD in MZ and DZ twins are shown in table 2. Pairwise concordance rates were significantly higher in MZ than DZ twins (27\% v 15\%; $\mathrm{p}=0.001)$. Casewise concordance rates were also significantly higher in MZ than DZ twins $(42 \% v 26 \%$; $<<0.001)$. The risk ratio of 1.6 suggests that MZ co-twins are one and a half times more likely to suffer from GORD if their co-twin has GORD compared with DZ co-twins.

The results of logistic regression analysis for risk factors for GORD expressed as odds ratios are shown in table 3. Increasing age and BMI were independently associated with GORD. Anticholinergic drug therapy, a history of smoking, and a parental family history of upper gastrointestinal disease were 
Table 3 Logistic regression analysis of potential risk factors for gastro-oesophageal reflux disease in the study population

\begin{tabular}{llc}
\hline Variable & Odds ratio $(95 \% \mathrm{Cl})$ & $\mathrm{p}$ Value \\
\hline Age (per y) & $1.03(1.02-1.03)$ & $<0.001$ \\
Anticholinergic drug therapy & $1.52(1.12-2.05)$ & 0.006 \\
Body mass index (per unit increase) & $1.11(1.09-1.13)$ & $<0.001$ \\
Ever smoked & $1.31(1.10-1.54)$ & 0.001 \\
Excess alcohol* & $0.99(0.99-1.00)$ & 0.67 \\
Sex & $0.91(0.68-1.22)$ & 0.52 \\
Oral contraceptive or HRT & $0.76(0.63-0.93)$ & 0.006 \\
Parental family history of upper GI disease & $1.46(1.22-1.74)$ & $<0.001$ \\
Right handed & $1.06(0.82-1.36)$ & 0.66 \\
\hline \multirow{2}{*}{ *Excess alcohol intake was defined as $>28$ units per week for a man and >21 units per week for a woman. } \\
HRT, hormone replacement therapy; Gl, gastrointestinal.
\end{tabular}

Table 4 Genetic modelling analysis for gastro-oesophageal reflux disease

\begin{tabular}{llccc}
\hline Model & $\mathrm{A}(95 \% \mathrm{Cl})$ & $\mathrm{C} / \mathrm{D}(95 \% \mathrm{Cl})$ & Difference in $\chi^{2}$ & $\mathrm{p}$ Value \\
\hline $\mathrm{ACE}$ & $0.68(0.34$ to 1.03$)$ & $-0.15(-0.42$ to 0.12$)$ & - & - \\
$\mathrm{CE}$ & - & $0.36(0.27$ to 0.44$)$ & 31.1 & $<0.001^{*}$ \\
$\mathrm{AE}$ & $0.50(0.39$ to 0.61$)$ & - & 2.4 & $0.12^{*}$ \\
$\mathrm{ADE}$ & $0.23(-0.26$ to 0.73$)$ & $0.30(-0.24$ to 0.84$)$ & - & - \\
\hline
\end{tabular}

$A$, additive genetic; $D$, dominant genetic; $C$, common environment; $E$, unique environment. *Compared with ACE model.

Table 5 Genetic modelling analysis for gastro-oesophageal reflux disease when corrected for confounders to best fitting model (AE)

\begin{tabular}{llr}
\hline & $\mathrm{A}(95 \% \mathrm{Cl})$ & $\mathrm{p}$ Value \\
\hline AE model & $0.43(0.32-0.55)$ & 0.085 \\
Age & $0.02(0.01-0.03)$ & $<0.001$ \\
Body mass index & $0.10(0.07-0.12)$ & $<0.001$ \\
Ever smoked & $0.15(-0.10-0.40)$ & 0.234 \\
Anticholinergic drug therapy & $0.22(-0.25-0.69)$ & 0.367 \\
\hline
\end{tabular}

$A$, additive genetic; $E$, unique environment.

also positively associated with GORD. Oral contraceptive or hormone replacement therapy was negatively associated with GORD. Excess alcohol intake, sex, handedness, and other drug treatments were not independent predictors.

The results of genetic modelling analysis are shown in table 4. Model fitting revealed that the effects of the shared environment of the twins (C) and the dominant genetic effect (D) could be dropped from the model without significantly worsening the $\chi^{2}$ goodness of fit statistic. However, additive genetic effects (A) could not be eliminated. A model containing only parameters for additive genetic factors (A) and the unique environment of the twins (E) best explained the variance in liability to GORD within this population.

Heritability for GORD was estimated to be 50\% (95\% confidence interval 39-61\%). Thus approximately half of the variance in liability to GORD is due to genetic factors.

The results of adjusting the model for potential confounding factors are shown in table 5. Age and BMI were the only confounders that significantly affected the estimate of genetic variation. Following adjustment for age and BMI, the proportion of phenotypic variance accounted for by genetic factors was reduced from $50 \%$ to $43 \%$.

The results were unchanged when male twins were dropped from the analysis, although there were too few data for a male only analysis.

\section{DISCUSSION}

Despite a wealth of literature detailing the pathophysiology of GORD, few studies have explored its underlying causes. However, a number of clinical associations have been reported. Obesity, for example, has been found to be an independent predictor of GORD symptoms in community based surveys. ${ }^{20}{ }^{21}$ Smoking also appears to be associated with GORD symptoms but no consistent link with alcohol consumption has been found.$^{20-22}$ Several prescription drugs decrease lower oesophageal sphincter (LOS) pressure and may potentially exacerbate or precipitate GORD. ${ }^{23}$ Data on the effect of increasing age is conflicting while sex is not believed to be an important factor. ${ }^{20-22}$

Two lines of evidence suggest the importance of familial factors in the aetiology of GORD. Firstly, a number of reports describe families with multiple members affected by symptomatic, endoscopic, or complicated GORD. ${ }^{56}$ Secondly, two case control studies have revealed aggregation of GORD symptoms in the families of patients with GORD. ${ }^{78}$ However, these studies were unable to examine the relative contributions of genetic and shared environmental influences to familial aggregation of GORD.

In the present study, we have shown that MZ twins are more likely to be concordant for GORD symptoms than DZ twins. As genetic factors are more likely to affect both of a pair of MZ twins than both of a pair of DZ twins, the increased concordance among MZ twins implies a significant genetic contribution to the aetiology of GORD. Genetic modelling suggests that half of the variation in liability to GORD relates to genetic factors. The combination of additive genetic factors and environmental influences unique to the individual provided the best model to explain the variation in GORD among the population studied. The unique environmental influences associated with GORD in the study population included the expected risk factors of age, BMI, and smoking. Anticholinergic drug therapy was also associated with GORD. Unexpectedly, GORD was less common in subjects taking oral contraceptive or hormone replacement therapy. Adjustment for confounding influences revealed that age and BMI made minor contributions to the heritability of GORD. As BMI is itself predominantly under genetic influence, the adjusted 
estimates will exclude genetic influences potentially shared between GORD and obesity.

It is interesting to speculate how a genetic predisposition to GORD is expressed. A number of factors contribute to the pathophysiology of GORD. Hiatus hernia impairs the barrier to reflux at the gastro-oesophageal junction ${ }^{24}$ and delays the clearance of refluxed acid from the oesophagus. ${ }^{25}$ Inherited congenital hiatus hernia has been reported in a family in which the father and all three children presented with GORD in the neonatal period. ${ }^{26}$ However, oesophageal shortening has been demonstrated in animal experiments in response to acid and hiatus hernia may therefore be the result of chronic gastro-oesophageal reflux rather than an underlying cause. ${ }^{27}$ Reduced LOS pressure is a common finding in patients with GORD, ${ }^{28}$ weakening the barrier to reflux during, for example, increases in intra-abdominal pressure. Ineffective oesophageal body peristalsis is also found in many patients with GORD ${ }^{29}$ and delays clearance of refluxed acid. Five members of a family with autosomal dominant inheritance of endoscopic oesophagitis underwent oesophageal manometry; all had reduced LOS pressure and two impaired peristalsis. ${ }^{30}$ However, in animals, reduced LOS pressure and impaired peristalsis can be caused by gastro-oesophageal reflux. ${ }^{31}$ The majority of episodes of acid reflux occur during transient LOS relaxation (TLOSR). ${ }^{32}$ However, TLOSR occur as frequently in asymptomatic subjects as in patients with GORD ${ }^{33}$ and differences in TLOSR frequency are unlikely to be the mechanism of the genetic predisposition to GORD. Finally, abnormalities of gastric function may be important. Reduced postprandial proximal gastric tone and delayed emptying of both solids and liquids from the proximal stomach have been described in patients with GORD. ${ }^{34}$ These changes permit the retention of acidic chyme in the fundus and cardia thereby facilitating acid reflux should barrier pressure fall.

Although the data from this study are consistent with multiple gene effects contributing to GORD, a number of case reports describe an autosomal dominant pattern of inheritance of GORD. ${ }^{5}{ }^{6}$ Furthermore, an association between a locus on chromosome 13q14 and paediatric GORD in five families with an autosomal dominant inheritance of this condition has been reported. ${ }^{35}$ However, a subsequent linkage study in six families with infant GORD and autosomal dominant inheritance has not found an association with this locus, suggesting that there is genetic heterogeneity in the inheritance of GORD. ${ }^{36}$

Cameron et al have recently examined the prevalence of GORD symptoms in a study of 8411 twin pairs over the age of 55 years in Sweden. ${ }^{9}$ Casewise concordance for GORD was $31 \%$ among female MZ twins, significantly higher than female DZ twins (21\%), confirming the significance of genetic factors in the aetiology of GORD. Heritability accounted for only 30\% of the liability to GORD in this study. Differences in methodology (telephone survey versus questionnaire) and in confounding factors among the populations studied (including age and nationality) may account for the differing heritability estimates.

Non-responders in this study were more likely to be younger and male. However, neither of these factors influences the prevalence of GORD symptoms. ${ }^{2}$ The prevalence of GORD symptoms in the study population was very similar to that reported in community surveys. ${ }^{12}$ Finally, the twins were asked for information on a number of different subjects and were unaware of the hypothesis being tested. Response bias is therefore unlikely to have affected the results of this study.

It is important to appreciate that the results of a study in twins may not be generalisable to singletons. However, the prevalence of a number of common medical conditions and lifestyle characteristics among twins from the St Thomas' Adult UK Twin Registry has been found to be very similar to a population drawn from general practice. ${ }^{37}$ Our study cannot be directly generalised to males as the twin population examined was largely female. The twin population has a female bias for historical reasons, as the rheumatological conditions initially examined are more common in women. However, Cameron et al found no difference in the concordance rates for female and male twins. ${ }^{9}$ The results are therefore unlikely to be sex specific.

In conclusion, in the present study we have shown that MZ twins are more likely to be concordant for GORD symptoms than DZ twins. The results indicate a substantial genetic contribution to the aetiology of GORD. Genetic modelling suggests that almost half of the variation in liability to GORD is due to multiple small genetic effects, which should stimulate the search for the genes responsible and potential targets for new therapies for GORD.

\section{ACKNOWLEDGEMENTS}

We are grateful to Bridget Gunson (Liver Laboratories, University Hospital, Birmingham) for initial data processing and analysis. We gratefully acknowledge financial support from Janssen Pharmaceuticals, Knoll, and Wyeth Laboratories. The Twin Research and Genetic Epidemiology Unit receives financial support from the Arthritis Research Campaign, British Heart Foundation, Chronic Disease Research Foundation, Wellcome Trust, and Sequenom Inc.

\section{Authors' affiliations}

I Mohammed, N J Trudgill, Department of Gastroenterology, Sandwell General Hospital, West Bromich, UK

F Cherkas, T D Spector, Twin Research and Genetic Epidemiology Unit, St Thomas' Hospital, London, UK

S A Riley, Department of Gastroenterology, Northern General Hospital, Sheffield, UK

\section{REFERENCES}

Thompson WG, Heaton KW. Heartburn and globus in apparently healthy people. Can Med Assoc J 1982;126:46-8.

2 Locke GR, Talley NJ, Fett SL, et al. Prevalence and clinical spectrum of gastroesophageal reflux: a population-based study in Olmsted County, Minnosta. Gastroenterology 1997;1 12:1448-56.

3 Lagergren J, Bergstrom R, Lindgren A, et al. Symptomatic gastroesophageal reflux as a risk factor for oesophageal adenocarcinoma. N Engl J Med 1999;340:825-31.

4 El-Serag HB, Mason AC, Petersen N, et al. Epidemiological differences between adenocarcinoma of the oesophagus and adenocarcinoma of the gastric cardia in the USA. Gut 2002;50:368-72.

5 Jochem VJ, Fuerst PA, Fromkes JJ. Familial Barrett's esophagus associated with adenocarcinoma. Gastroenterology 1992;102:1400-2.

6 Eng C, Spechler SJ, Ruben R, et al. Familial Barrett esophagus and adenocarcinoma of the gastroesophageal junction. Cancer Epidemiol adenocarcinoma of the gastroes
Biomarkers Prev 1993;2:397-9.

7 Trudgill NJ, Kapur KC, Riley SA. Familial clustering of reflux symptoms. Am J Gastroenterol 1999;94:1172-8.

8 Romero Y, Cameron AJ, Locke GR, et al. Familial aggregation of gastroesophageal reflux in patients with Barrett's esophagus and esophageal adenocarcinoma. Gastroenterology 1997;1 13:1449-56.

9 Cameron AJ, Lagergren J, Henriksson C, et al. Gastroesophageal reflux disease in monozygotic and dizygotic twins. Gastroenterology $2001 ; 122: 55-9$

10 St Thomas' Adult UK Twin Registry. Twin Res 1998;1:47.

11 Spector TD, Cicuttini F, Baker J, et al. Genetic influences on osteoarthritis in women: a twin study. BMV 1996:312:940-4.

12 Martin NG, Martin PG. The inheritance of scholastic abilities in a sample of twins. Ascertainments of the sample and diagnosis of zygosity. Ann Hum Genet 1975;39:213-18.

13 Kyvik KO. Generalisability and assumptions of twin studies. In: Spector TD, Sneider H, Macgregor AJ, eds. Advances in Twin and Sib-pair Analysis. London: Greenwich Medical Media, 2000: 67-77.

14 Macgregor AJ. Practical approaches to account for bias and confounding in twin data. In: Spector TD, Sneider H, Macgregor AJ, eds. Advances in Twin and Sib-pair Analysis. London: Greenwich Medical Media, 2000:35-52.

15 Neale MC, Cardon LR. Methodology for Genetic Studies of Twins and Families. Dordrecht: Kluwer Academic Publishers, 1992.

16 Sneider H, Boomsma DI, Van Doornen LIP. Heritability of respiratory sinus arrythmia: dependency on task and respiration rate. Psychophysiology 1997;34:317-28.

17 Falconer DS. Introduction to Quantitive genetics. Harlow: Longman Scientific and Technical, 1989.

18 Sham PC, Walters EE, Neale MC, et al. Logistic regression analysis of twin data: estimation of parameters of the multifactorial liability-threshold model. Behav Genet 1994;24:229-38.

19 Intercooled Stata for Windows 95 (version 5.0). College Station, Texas: Statacorp, 1997. 
20 Locke GR, Talley NJ, Fett SL, et al. Risk factors associated with symptoms of gastroesophageal reflux. Am J Med 1999:106:642-9.

21 Isolauri J, Laippala P. Prevalence of symptoms suggestive of gastro-oesophageal reflux disease in an adult population. Ann Med 1995;27:67-70.

22 Haque $\mathrm{M}$, Wyeth JW, Stace $\mathrm{NH}$, et al. Prevalence, severity and associated features of gastro-oesophageal reflux and dyspepsia: a population based study. N Z Med J 2000;113:178-81.

23 Ogorek CP, Cohen S. Gastroesophageal reflux disease: new concepts in pathophysiology. Gastroenterol Clin North Am 1989;18:275-92.

24 loan S, Kahrilas PJ. Impairment of esophageal emptying with hiatal hernia. Gastroenterology 1991;100:596-605.

25 Sloan S, Kahrilas PJ. Determinants of gastroesophageal junction incompetence: hiatal hernia, lower esophageal sphincter, or both? Ann Intern Med 1992:117:977-82.

26 Chana J, Crabbe DCG, Spitz L. Familial hiatus hernia and gastro-oesophageal reflux. Eur J Pediatr Surg 1996;6:175-6.

27 Paterson WG, Kolyn DM. Esophageal shortening induced by short-term intraluminal acid perfusion in opossum: a cause for hiatus hernia? Gastroenterology 1994;107:1736-40.

28 Behar J, Biancani P, Sheahan DG. Evaluation of esophageal tests in the diagnosis of reflux esophagitis. Gastroenterology 1976;71:9-15.

29 Kahrilas PJ, Dodds WJ, Hogan WJ, et al. Esophageal peristaltic dysfunction in peptic esophagitis. Gastroenterology 1986;91:879-904.
30 Crabb DW, Berk MA, Hall TR, et al. Familial gastroesophageal reflux and development of Barrett's esophagus. Ann Intern Med $1985 ; 103: 52-4$

31 Eastwood GL, Castell DO, Higgs RH. Experimental esophagitis in cats impairs lower esophageal sphincter pressure. Gastroenterology 1975;69: 146-53

32 Dodds WJ, Dent J, Hogan WJ, et al. Mechanisms of gastroesophageal reflux in patients with reflux esophagitis. N Engl J Med $1982 \cdot 307 \cdot 1547-52$

33 Trudgill NJ, Riley SA. Transient lower esophageal sphincter relaxations are no more frequent in patients with gastro-oesophageal reflux disease than in asymptomatic volunteers. Am J Gastroenterol 2001;96:2569-74

34 Penagini R, Hebbard G, Horowitz $M$, et al. Motor function of the proximal stomach and visceral perception in gastro-oesophageal reflux disease. Gut 1998:42:251-7.

35 Hu FZ, Preston RA, Post JC, et al. Mapping of a gene for severe pediatric gastroesophageal reflux to chromosome 13q14. JAMA 2000;284:325-34

36 Orenstein SR, Shalaby TM, Pfuetzer RH, et al. Autosomal dominant infant GERD: exclusion of a $13 q 14$ locus in 6 well-characterized families suggests genetic heterogeneity. Gastroenterology 2001;120:A21 1 .

37 Andrew T, Hart DJ, Sneider $\mathrm{H}$, et al. Are twins and singletons comparable? A study of disease-related and lifestyle characteristics in adult women. Twin Res 2001;4:464-77.

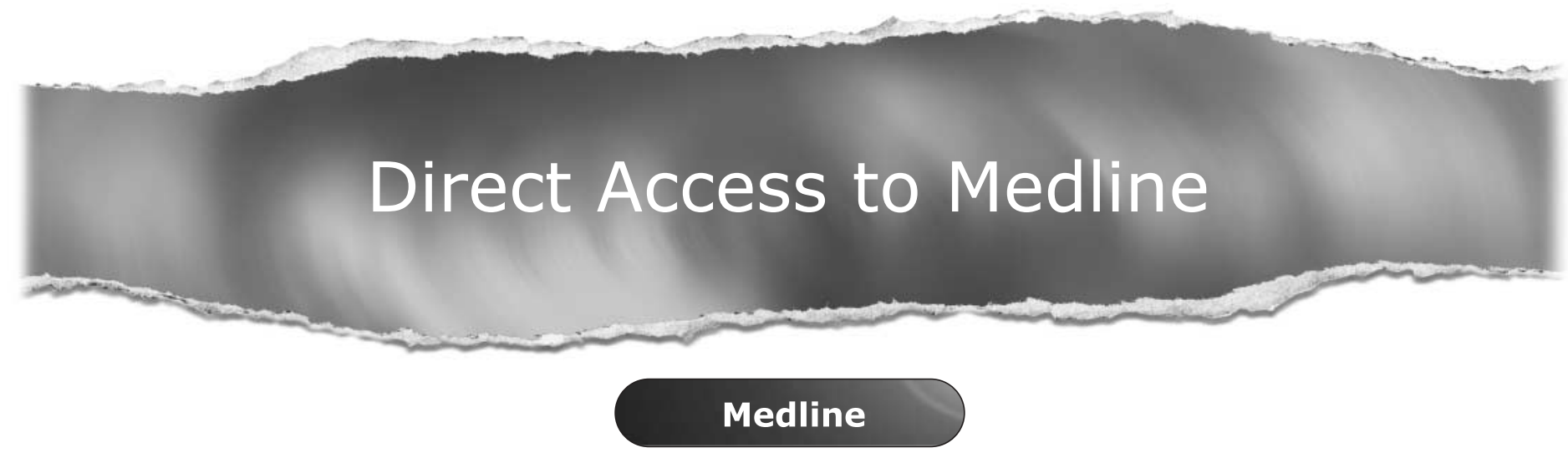

Link to Medline from the homepage and get straight into the National Library of Medicine's premier bibliographic database. Medline allows you to search across 9 million records of bibliographic citations and author abstracts from approximately 3,900 current biomedical journals.

\section{www.gutjnl.com}

